\title{
Communication
}

\section{Who is responsible for embodied $\mathrm{CO}_{2}$ ?}

\author{
Hans Sanderson ${ }^{1, *}$
}

1* Aarhus University, Department of Environmental Science, 4000 Roskilde, Denmark; sanderson@envs.au.dk Correspondence: sanderson@envs.au.dk

\begin{abstract}
With the Paris Agreement countries are obliged to report greenhouse gas (GHG) emission reductions which will ensure that the global temperature increase is maintained well below $2 \mathrm{C}$. The Parties will report their Nationally Determined Contributions in terms of plans and progress towards these targets during the postponed COP26 in Glasgow in November 2021. These commitments however do not take significant portions of the consumption related emissions related to countries imports in to account. Similarly, the majority of companies that report their emissions to CDP also do not account for their embodied value-chain related emissions. Municipalities on the path towards carbon neutrality in accordance with the methods outlined by $\mathrm{C} 40$ also do not include imported and embodied $\mathrm{CO} 2$ in their total emission tallies. So, who is responsible for these emissions - the producer or the consumer? How can we ensure that the NDC's, municipalities and companies reduction targets share the responsibility of the emissions in the value-chain, so that the targets and plans become, sustainable, climate fair, and just in global value chains?
\end{abstract}

Keywords: Sustainability; Climate; Trade; Models; Emissions; Value Chain; Justice

\section{Sustainability and un-goods}

The first United Nations (UN) global sustainability conference was held almost 50 years ago in Stockholm in 1972. The meeting report contains more than 100 recommendations on how to ensure global sustainability in the decades to come. Among these are a few critical pillars: 1) that sustainability is a global responsibility; 2) that sustainability is not only protection of the environment but aimed at ensuring that future generations can live and prosper, and hence that the economic model behind the exploitation of natural resources needs to be sustainable in the long term - not just short term; 3 ) that sustainability needs to be based on social justice between geographies, peoples, and generations; 4) that the full environmental embedded costs related to the production of goods are reflected in the price of a good - that the externalities are internalized in the price [1]. These recommendations still under-pin the global efforts and in wake of Covid-19 at the UN level, who have formulated six recommendations for the recovery, among these that: $a$ ) Investments must accelerate the decarbonization of all aspects of our economy; $b$ ) Invest in sustainable solutions - fossil fuel subsidies must end and polluters must pay for their pollution; c) cooperation - no country can succeed alone [2].

The implications of sustainability and climate transition to a low carbon economy challenges our global economic models and cooperation. In 1992, the German scientist Ulrich Beck published his seminal book, Risk Society, towards a new modernity. He argues that one can view our society via an inverse welfare economic perspective where societal transaction and economy are shifting risks, or undesired un-goods, between societal actors. Hence, in addition to optimizing welfare there is similarly a transaction to minimize risks and un-goods taking place [3]. In a low carbon economy and climate change context the un-good is the externalities, the unpaid pollution by the producer - the Greenhouse Gas (GHG) emissions embodied in traded products and services. The question is how to accommodate the explicit transaction of GHG emissions in global trade and emission inventories to enable a transition to a low carbon economy? 


\section{GHG emissions and transition to a low carbon economy}

Countries report their national emission inventories to the UNFCCC [4] and follow the guidelines laid down in the technical annexes of the Kyoto Protocol Art. 5, 7, and 8. These relate to direct and indirect emissions related and anthropogenic (in broad terms related to energy use and incineration) and natural emissions (primarily related to agriculture) of GHGs. There is however, no requirement to account or report imported consumption-based emissions - i.e. the emissions embodied in a countries imports. The United Kingdom (UK) is one of very few countries who have assessed their consumptionbased emissions. The figure below depicts the GHG emissions embedded in imported goods and services compared to UK produced ditto, revealing that the embedded and not accounted for GHG is comparable to the domestic GHG emissions. There are no formal guidelines for this analysis and hence also higher inaccuracies and uncertainties [5].

Million tonnes $\mathrm{CO}_{2}$ equivalents

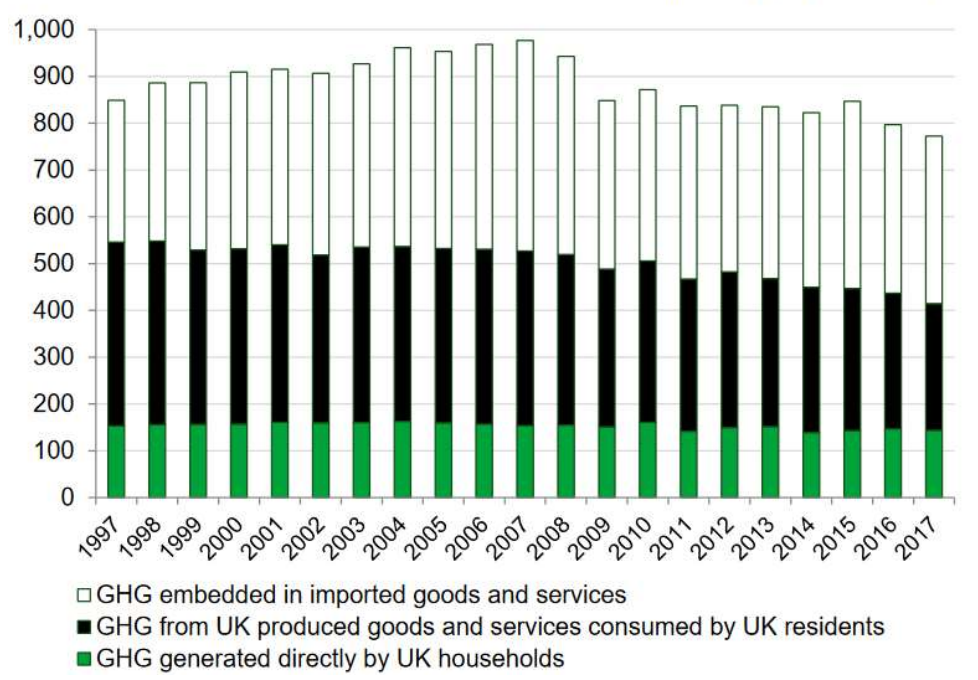

Figure 1. UK GHG emissions related to consumption 1997-2017 [5].

Municipalities, are increasingly also assessing and communicating their GHG emissions, carbon footprint and $\mathrm{CO}_{2}$ neutrality. There are no formal guidelines for these analysis at municipal level, hence the C40 cooperation [6] is widely viewed as the 'Gold Standard' for cities and municipalities to account their GHG emissions. Embodied GHG in products and services imported to the city or municipality via their value- and supplychain transactions are however not included in the C40 inventorying methodology [7]. Since, C40 essentially follow a downscaled and simplified methodology of the national inventory described above, it can be assumed that for e.g. industrialized cities and municipalities the that distribution between assessed and non-assessed emissions are on par with that of the UK - that roughly $50 \%$ of emissions are not accounted for.

Companies are reporting their GHG emissions to CDP [8], in 2020 a total of 9526 companies representing more than $50 \%$ of the global market capitalization reported their GHG emissions to CDP. The companies assess their emissions based on the World Resource Institute (WRI) guidelines set out in the Greenhouse gas protocol [9]. Scope 3 (value-chain related emissions) is more complex and challenging than scopes $1 \& 2$ (direct and indirect emissions), hence scope 3 reporting to CDP is also more limited and less mature with only $78 \%$ of companies reporting at least one of the 15 Scope 3 categories and only $23 \%$ engaging their value-chain in obtaining reduction targets. Emissions located in Scope 3 and the supply chain are however, on average approximately four times as high as those from direct operations for a reporting company [10]. Considerable GHG emissions thus remain unaccounted for at corporate level as well. 


\section{Sustainable reporting}

Transparency in the market is essential to maintain financial stability. It is therefore important that companies, municipalities and countries accurately and sustainably assess and disclose their full GHG emissions to enable investors to risk manage their investments. This will allow externalities to be incorporated in the price of goods and services and hence meet a prerequisite identified decades ago in Stockholm at the first UN global sustainability conference. The devil is in the detail in these analyses, and we have to realize that we will all need to learn new analysis methods and data in the market place in order for the market to facilitate transition to a low carbon economy and thereby address the global challenge of raising GHG emissions. The Science Based Target Initiative [11] is an example of how companies can comply with the Paris Agreement targets and require incorporation of Scope 3 emissions. Similar frameworks could be developed for municipalities mandating inclusion of Scope 3 emissions. Dawkins et al. (2019), demonstrate at national level how environmentally extended multi-regional input-output models (MRIO) can be used to determine countries, with Sweden as the case, consumption-based emissions [12]. A decade ago, Peters (2010) showed trade-offs between applying different methodological approaches pertaining to the assessment of embodied GHG from inputoutput models to Life Cycle Analysis (LCA) depending on the type of organization being assessed, where environmentally extended input-output models (EEIO) are relevant at large national scales and LCA are more relevant at corporate scales [13].

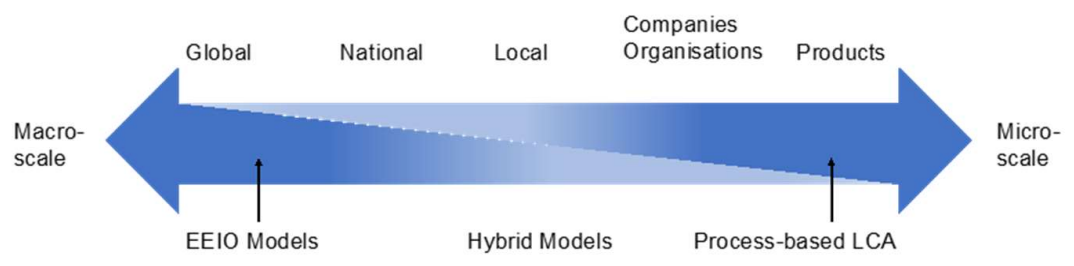

Figure 2: GHG assessment model types [13].

\section{Conclusions}

The good news is that that we have identified the need for sustainable GHG analysis and reporting, and that we can do this via adapting and updating existing systems thinking of interconnected and interdependent systems in regard to global trade and warming. In addition, it seems like there is a public demand for sustainable and just GHG responsibility as well as emerging political will to increase mitigation ambitions among the largest economies in the world (EU new climate law; China carbon neutrality in in 2060, and the President-elect Biden administration in the US). It is therefore important for the COP26 to insist on just and sustainable accounting of embodied and imported GHG globally and to further the development of analytical methods to account and disclose these transparently to ensure a transition to a low carbon economy and reaching Paris Agreement targets. This transitional risk is in my view the biggest and most urgent risk climate change represent to society today - the adaptation to the needed aggressive mitigation. There is a need for science to contribute to the development of sound and applicable assessment methods as well as support the countries, municipalities and companies in the transition of their economic and business models to a low carbon economy. The EU is already considering a new carbon tax on imports, with the aim that if differences in levels of ambition worldwide persist regarding decarbonization, as the EU increases its climate ambition, the EU Commission will propose a carbon border adjustment mechanism to reduce the risk of carbon leakage where needed. The tax will contribute to global decarbonisation while ensuring that the competitiveness of EU industry is not jeopardised 
by carbon leakage [14]. In other words, clarifying the 'un-good' [3] inherent in any trade and allowing the externalities to be internalized in prices in support of sustainability [1].

Funding: This research received no external funding.

Acknowledgments: Thomas Stridsland, Aarhus University, and Karin Darville, Gladsaxe Musikog Billedskole, for discussions leading up to this communication.

Conflicts of Interest: The author declares no conflict of interest.

\section{References}

1. UN 1972: AF Conf 48/14 Rev1. URL: http://undocs.org/en/A/CONF.48/14/Rev.1 (accessed on 28 December 2020).

2. UN 2020: SDG 13: URL: https://www.un.org/sustainabledevelopment/climate-change/ (accessed on 28 December 2020).

3. Ulrich Beck, 1992, The Risk Society - towards a new modernity, SAGE, London UK.

4. UNFCCC, 2020: Paris Agreement URL: https://unfccc.int/process-and-meetings/the-paris-agreement/the-paris-agreement (accessed on 28 December 2020)

5. Department of Environment, Food and Rural Affairs, 2017. UKs carbon footprint 1997-2017. URL: https://www.gov.uk/government/statistics/uks-carbon-footprint (accessed on 28 December 2020).

6. C40 network: URL: https://www.c40.org/ (accessed on 28 December 2020).

7. C40 network, 2019: Defining carbon neutrality for cities and managing residual emissions. URL: https://c40-production-images.s3.amazonaws.com/researches/images/76_Carbon_neutrality_guidance_for_cities_20190422.original.pdf?1555946416. (accessed on 28 December 2020).

8. CDP, 2020: URL: https://www.cdp.net/en (accessed on 28 December 2020).

9. GHG Protocol, 2020, URL: https://ghgprotocol.org/ (accessed on 28 December 2020).

10. CDP, 2018, Global Supply Chain report: URL: https://www.cdp.net/en/research/global-reports/global-supply-chain-report-2018 (accessed on 28 December 2020).

11. Science Based Targets Initiative, 2020: URL: https://sciencebasedtargets.org/ (accessed on 28 December 2020).

12. Dawkins E., Moran D., Palm V., Wood R., Björk I. 2019. The Swedish footprint: A multi-model comparison. Jour. Cleaner Prod. Vol. 209., 1578-1592.

13. Peters G. 2010. Carbon footprints of embodied carbon at multiple scales. Current Opinion in Environ. Sustain., Vol 2, Iss. 4, 245250.

14. EU, 2020. Carbon boarder adjustment mechanism. URL: EU, 2020. Carbon boarder adjustment mechanism. https://www.europarl.europa.eu/committees/da/carbon-border-adjustment-mechanism/product-details/20201009CDT04181 (accessed on 28 December 2020). 